Correction: Association between delayed gastric emptying and upper gastrointestinal symptoms: a systematic review and meta-analysis

Vijayvargiya P, Jameie-Oskooei S, Camilleri M, et al. Association between delayed gastric emptying and upper gastrointestinal symptoms: a systematic review and meta-analysis. Gut 2019;68:804-13. doi: 10.1136/gutjnl-2018-316405

Figure 2 has been corrected:

\section{A. Nausea}

\section{Studies}

Ardila-Hani, 2013 (46)

Bharucha, 2009 (44)

Cherian, 2010 (50)

Marie, 2012 (58)

Park, 2017 (5)

Sfarti, 2010 (64)

Stanghellini, $2002(65)$

Stanghellini, $2003(66)$

Talley, 2006 (68)

Vanheel, $2017(69)$

Borges, 2013 (49)

Guo, 2012 (54)

Hyett, 2009 (55)

Karamanolis, 2007 (56)

Ron, 2011 (62)

Talley, 2001 DM population (67)

Talley, 2001 UGI Sx population (67)

Subgroup no $\left(I^{2}=15.04 \%, P=0.315\right.$

Overall $\left(I^{2}=10.62 \%, P=0.330\right)$

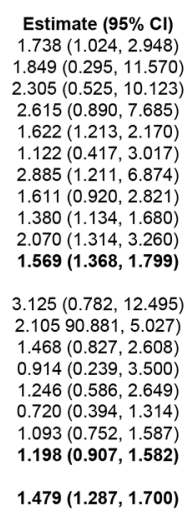

\section{B. Vomiting}

\section{Studies}

Ardila-Hani, 2013 (46)

Bharucha, 2009 (44)

Marie, 2012 (58)

Park, 2017 (5)

Stanghellini, 2002 (65)

Stanghellini, $2003(66)$

Subgroup yes $\left(I^{2}=14.05 \%, P=0.323\right)$

Boltin, 2014 (48)

Guo, 2012 (54)

Hyett, 2009 (55)

Karamanolis, 2007 (56)

Ron, 2011 (62)

Talley, 2001 DM population (67)

Talley, 2001 UGI Sx population (67)

Subgroup no $\left(I^{2}=46.67 \%, P=0.081\right)$

Overall $\left({ }^{2}=62.77 \%, P=0.001\right)$

\section{Bloating}

\section{Studies}

Ardila-Hani, 2013 (46)

Bharucha, 2009 (44)

Cuomo, 2001 (51)

Marie, 2012 (58)

Park, 2017 (5)

Stanghellini, $2002(66)$

Stanghellini, 2002

Talley, 2006 (68)

Subgroup yes $\left(I^{2}=82.01 \%, P=0.000\right)$

Boltin, 2014 (48)

Guo, 2012 (54)

Hyett, 2009 (55)

Karamanolis, $2007(56)$

Ron, 2011 (62)

Talley, 2001 DM population (67)

Talley, 2001 UGI Sx population (67)

Subgroup no $\left(I^{2}=44.88 \%, P=0.092\right.$

Overall $\left(I^{2}=73.18 \%, P=0.000\right)$

Estimate $(95 \% \mathrm{Cl})$ $2.048(1.275,3.290)$ $1.714(0.741,3.964)$ $36.600(2.019,663.367)$ $2.308(1.773,3.005)$ $1.773(0.403,7.797)$ $0.900(0.178,4.548)$ $1.341(0.640,2809)$ $2.031(1.555,2.653)$

$1.326(0.737,2.383)$ $1.765(0.607,5.127)$ $1.385(0.760,2.522)$ $1.133(0.317,4.047)$ $2.167(0.886,5.299)$ $0.570(0.352,0.923)$ $1.198(0.828,1.735)$ $1.173(0.837,1.642)$

$1.479(1.099,1.990)$

Estimate (95\% Cl) Estimate $(95 \% \mathrm{Cl})$
$0.906(0.523,1.570)$ $0.906(0.523,1.570)$ $2200(1.00,4.840)$

$5.754(1.716,19.298)$

$0.754(1.716,19.298)$

$7.087(2.233,22.492)$

$1.087(1.244,3.174)$

$1.930(1.219,1.920)$

$1.830(1.094,3.060)$

$1.644(1.080,2.488)$

$3.096(1.562,6.137)$

$3.096(1.562,6.137)$
$1.714(0.607,4.838)$

$1.553(0.866,2.785)$

$0.546(0.806,1.739)$

$1.353(0.628,2.913)$

$0.806(0.214,3.041)$

$1.357(0.865,2.129)$

$1.504(1.108,2.041)$

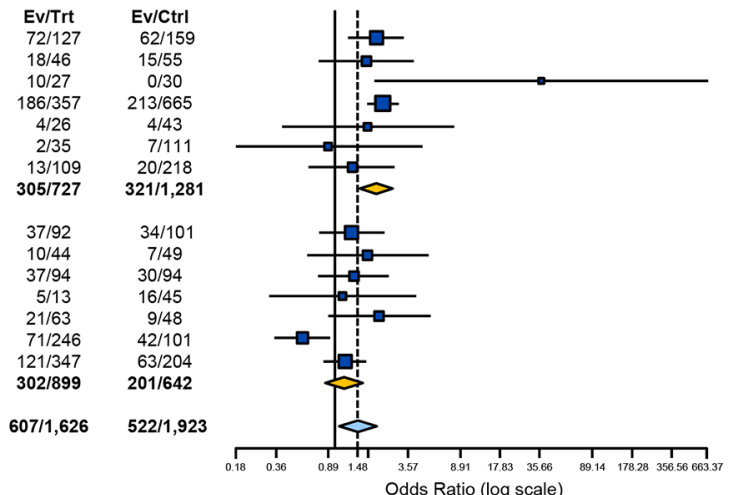

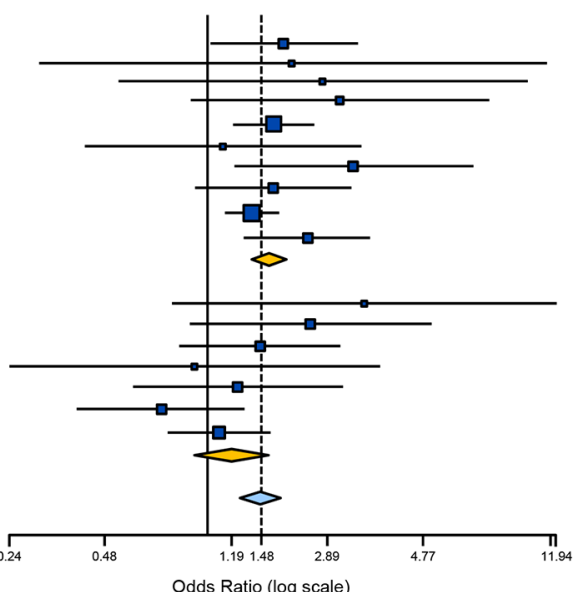

Odds Ratio (log scale)

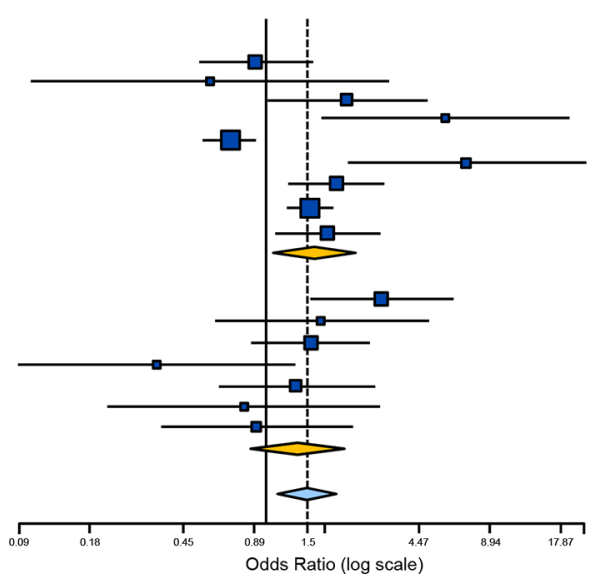

(c) Author(s) (or their employer(s)) 2019. No commercial re-use. See rights and permissions. Published by BMJ.

Gut 2019;68:1908. doi:10.1136/gutjnl-2018-316405corr1

Check for updates 